\title{
Commentary: Playing the computer game tetris prior to viewing traumatic film material and subsequent intrusive memories: examining proactive interference
}

\author{
Angelica B. Ortiz de Gortari * and Mark D. Griffiths \\ International Gaming Research Unit, Psychology Division, Nottingham Trent University, Nottingham, UK
}

Keywords: post-traumatic stress disorder, visual intrusions, video Games, game transfer phenomena, trauma prevention, intrusive memories

\section{A Commentary on}

Playing the computer game tetris prior to viewing traumatic film material and subsequent intrusive memories: examining proactive interference

by James, E. L., Zhu, A. L., Tickle, H., Horsch, A., and Holmes, E. A. (2015b). J. Behav. Ther. Exp. Psychiatry. doi: 10.1016/j.jbtep.2015.11.004

OPEN ACCESS

Edited by:

Anna Abraham

Leeds Beckett University, UK

Reviewed by:

Kata Pauly-Takacs,

Leeds Beckett University, UK

*Correspondence:

Angelica B. Ortiz de Gortari

angelica@

gametransferphenomena.com

Specialty section:

This article was submitted to

Psychopathology,

a section of the journal

Frontiers in Psychology

Received: 21 December 2015 Accepted: 09 February 2016

Published: 23 February 2016

Citation:

Ortiz de Gortari $A B$ and Griffiths $M D$

(2016) Commentary: Playing the

computer game tetris prior to viewing

traumatic film material and

subsequent intrusive memories:

examining proactive interference.

Front. Psychol. 7:260.

doi: 10.3389/fpsyg.2016.00260
Unwanted visual intrusions are characteristic of Post-Traumatic Stress Disorder (American Psychiatric Association, 2013). One innovative intervention for inhibiting unwanted intrusions is playing the Tetris videogame, described as a "cognitive vaccine" in preventing intrusions after traumatic events (Holmes et al., 2009). Playing Tetris consumes heavy visuospatial working memory resources that potentially compete with cognitive resources required for elaboration of visual imagery. Since Holmes et al.'s (2009) study, other studies have used Tetris to inhibit intrusive imagery (Holmes et al., 2010; Skorka-Brown et al., 2014, 2015; James et al., 2015a,b). However, these have not assessed the role of videogame content after playing in relation to Game Transfer Phenomena (GTP) (Ortiz de Gortari and Griffiths, 2014a,b,c, 2015a,b).

GTP research has investigated non-volitional experiences (e.g., altered sensorial perceptions and automatic mental processes/behaviors) mostly experienced after gaming. Gamers often report sensorial (visual/auditory) intrusions after playing (e.g., visual and auditory imagery, hallucinations) (Ortiz de Gortari et al., 2011; Ortiz de Gortari and Griffiths, 2014a,b). In a survey of 2362 gamers, most (77\%) had visualized images from a variety of videogames (including tilepuzzle games) with closed-eyes, and one-third (31\%) had visualized images with open-eyes (Ortiz de Gortari and Griffiths, 2015b). Other studies have experimentally induced videogame-related visualizations at sleep onset (Stickgold et al., 2000; Wamsley et al., 2010; Kusse et al., 2012).

James et al. (2015a,b) study was the first to make explicit reference to GTP (referred to as the "Tetris effect" [TE]). Ortiz de Gortari and Griffiths (2012) argued the TE term is misleading as it suggests repetition is the core of transfer effects. However, other factors are involved. Research concerning GTP makes the distinction between sensorial modalities facilitating the assessment of non-volitional phenomena with videogame content that occur along the continuum from mild to severe (Ortiz de Gortari and Griffiths, under review). Moreover, the descriptive constructs of GTP are empirically based on analysis of $3500+$ gamers and have been examined via confirmatory factor analysis demonstrating good reliability and validity (Ortiz de Gortari et al., 2015).

James et al. (2015a,b) tested if playing Tetris offered a protective mechanism against reexperiencing traumatic events. Healthy participants $(n=56)$ were randomly assigned to either playing Tetris for $11 \mathrm{~min}$, or doing nothing before exposure to a 12-min traumatic film. Image-base 
memories about the film were then registered in a 1-week dairy. However, playing Tetris as a proactive interference task before watching the film did not show significant results. James and colleagues offered different explanations including: (i) duration of the task in relation to film length, (ii) temporal contingencies between the tasks, (iii) differences between the task types, (iv) videogame types used, and (v) reactivation of gameplay during the film for aided interference. These explanations are discussed in relation to GTP literature.

\section{DURATION OF TASK IN RELATION TO FILM LENGTH}

Playing Tetris for $11 \mathrm{~min}$ may not have been long enough to compete with the consolidation of memory of the 12-min film. GTP are significantly more likely to occur when playing 3-6 h. Only $4 \%$ of gamers reported GTP when playing sessions shorter than 1-h (Ortiz de Gortari and Griffiths, 2015a). Laboratory experiments have taken days of playing to induce game-related visualizations at sleep onset (Stickgold et al., 2000; Wamsley et al., 2010; Kusse et al., 2012).

\section{TEMPORAL CONTINGENCIES BETWEEN GAMING AND FILM WATCHING}

The tasks were performed minutes apart from each other. GTP mostly occurs soon after stopping playing but gamers have also reported GTP days after playing (Ortiz de Gortari and Griffiths, 2014c). In most cases, duration of experience is very short (seconds/minutes) but in some cases hours or longer.

\section{DIFFERENCES BETWEEN THE TASKS}

Previous studies have suggested that similar tasks aid interference (Bunting, 2006). Realistic videogames may reduce the differences between the tasks. Since playing videogames requires additional perceptual/motor skills than watching a passive film, it may be that gaming is more potent as an interference task, particularly if the subjective sense of presence in the virtual world is induced.

\section{TYPE OF VIDEOGAME USED AS INTERFERENCE TASK AND EMOTIONAL CONTENT OF FILM}

The unrealistic (geometric) Tetris content may have been overwritten by the film's traumatic images. Visualization of stereotypical games induced at sleep onset are characterized by lack of emotion, assuming that the amygdala and the reward

\section{REFERENCES}

American Psychiatric Association (2013). Diagnostic and Statistical Manual of Mental Disorders (DSM-5). Arlington, VA: American Psychiatric Association. system are not involved (Kusse et al., 2012). In GTP research, emotions in tile-matching puzzle-games are incomparable to emotions in realistic videogames (Ortiz de Gortari and Griffiths, 2014a).

\section{REACTIVATION OF GAMEPLAY DURING THE FILM FOR AIDED INTERFERENCE}

The use of cue reminders may have potential in reviving videogame content. In many cases, thoughts and altered perceptions are triggered by game-related cues (Ortiz de Gortari and Griffiths, 2014a). Attentional bias toward game-related cues has been demonstrated in experiments (Metcalf and Pammer, 2011). GTP have been reported in variety of videogame genres particularly those that have very realistic graphics and settings. Therefore, more realistic games may aid associations between real life stimuli and videogame content, and may be more effective in competing with memories of traumatic events.

\section{CONCLUSION}

In summary, playing Tetris is not only an effective visuospatial task (overloading working memory resources needed for imagery-formation while playing), but as demonstrated in GTP studies, videogame content stays active after playing (e.g., mental imagery, sensory perceptions), and may offer additional benefits for managing unwanted intrusions. GTP may potentially strengthen effects of interference tasks but should be used cautiously, because videogame content not only targets unwanted intrusions, but also influences individual cognitions, perceptions, and behaviors in day-to-day contexts (e.g., attention bias, lack of task awareness, control inhibition failures) (Ortiz de Gortari and Griffiths, 2015a). Moreover, distress and dysfunction have been reported with GTP (Ortiz de Gortari and Griffiths, 2015b, under review).

Further, research needs conducting to identify: (i) videogames that are most effective, (ii) playing duration, (iii) factors that reduce intervention efficacy and strategies to control them, and (iv) individuals that may benefit the most from such intervention. While using videogames as intervention tools for preventing unwanted imagery from traumatic experiences has potential, therapeutically it is still at an early stage.

\section{AUTHOR CONTRIBUTIONS}

AO had the initial idea and wrote the first draft of the paper. Both authors revised the paper critically, edited, and agree on the final version. MG edited down the final draft version. 
for trauma? A proposal from cognitive science. PLoS ONE 4:e4153. doi: 10.1371/journal.pone. 0004153

Holmes, E. A., James, E. L., Kilford, E. J., and Deeprose, C. (2010). Key steps in developing a cognitive vaccine against traumatic flashbacks: visuospatial tetris versus verbal pub quiz. PLoS ONE 5:e13706. doi: 10.1371/journal.pone.0013706

James, E. L., Bonsall, M. B., Hoppitt, L., Tunbridge, E. M., Geddes, J. R., Milton, A. L., et al. (2015a). Computer game play reduces intrusive memories of experimental trauma via reconsolidation-update mechanisms. Psychol. Sci. 26, 1201-1215. doi: 10.1177/0956797615583071

James, E. L., Zhu, A. L., Tickle, H., Horsch, A., and Holmes, E. A. (2015b). Playing the computer game Tetris prior to viewing traumatic film material and subsequent intrusive memories: examining proactive interference. J. Behav. Ther. Exp. Psychiatry. doi: 10.1016/j.jbtep.2015.11.004. [Epub ahead of print].

Kusse, C., Shaffii-LE Bourdiec, A., Schrouff, J., Matarazzo, L., and Maquet, P. (2012). Experience-dependent induction of hypnagogic images during daytime naps: a combined behavioural and EEG study. J. Sleep Res. 21, 10-20. doi: 10.1111/j.1365-2869.2011.00939.x

Metcalf, O., and Pammer, K. (2011). Attentional bias in excessive massively multiplayer online role-playing gamers using a modified Stroop task. Comput. Human Behav. 27, 1942-1947. doi: 10.1016/j.chb.2011.05.001

Ortiz de Gortari, A. B., Aronsson, K., and Griffiths, M. D. (2011). Game Transfer Phenomena in video game playing: a qualitative interview study. Int. J. Cyber Behav. Psychol. Learn. 1, 15-33. doi: 10.4018/ijcbpl.2011070102

Ortiz de Gortari, A. B., and Griffiths, M. D. (2012). "An introduction to Game Transfer Phenomena in video game playing," in Video Game Play and Consciousness, ed J. I. Gackenbach (Hauppauge, NY: Nova Publisher), 223-250.

Ortiz de Gortari, A. B., and Griffiths, M. D. (2014a). Altered visual perception in Game Transfer Phenomena: an empirical self-report study. Int. J. Hum. Comput. Interact. 30, 95-105. doi: 10.1080/10447318.2013. 839900

Ortiz de Gortari, A. B., and Griffiths, M. D. (2014b). Auditory experiences in Game Transfer Phenomena: an empirical self-report study. Int. J. Cyber Behav. Psychol. Learn. 4, 59-75. doi: 10.4018/ijcbpl.2014010105

Ortiz de Gortari, A. B., and Griffiths, M. D. (2014c). Automatic mental processes, automatic actions and behaviours in Game Transfer Phenomena: an empirical self-report study using online forum data. Int. J. Ment. Health Addict. 12, 1-21. doi: 10.1007/s11469-014-9476-3
Ortiz de Gortari, A. B., and Griffiths, M. D. (2015a). Game Transfer Phenomena and its associated factors: an exploratory empirical online survey study. Comput. Human Behav. 51, 195-202. doi: 10.1016/j.chb.2015.04.060

Ortiz de Gortari, A. B., and Griffiths, M. D. (2015b). "Prevalence and characteristics of Game Transfer Phenomena," in Paper Presented at the ITAG 2015: Interactive Technologies and Games - Education, Health and Disability (Nottingham).

Ortiz de Gortari, A. B., Pontes, H. M., and Griffiths, M. D. (2015). The Game Transfer Phenomena Scale: an instrument for investigating the nonvolitional effects of video game playing. Cyberpsychol. Behav. Soc. Netw. 10, 588-594. doi: 10.1089/cyber.2015.0221

Skorka-Brown, J., Andrade, J., and May, J. (2014). Playing 'Tetris' reduces the strength, frequency and vividness of naturally occurring cravings. Appetite 76, 161-165. doi: 10.1016/j.appet.2014.01.073

Skorka-Brown, J., Andrade, J., Whalley, B., and May, J. (2015). Playing Tetris decreases drug and other cravings in real world settings. Addict. Behav. 51, 165-170. doi: 10.1016/j.addbeh.2015.07.020

Stickgold, R., Malia, A., Maguire, D., Roddenberry, D., and O'Connor, M. (2000). Replaying the Game: hypnagogic images in normals and amnesics. Science 290, 350-353. doi: 10.1126/science.290.5490.350

Wamsley, E. J., Perry, K., Djonlagic, I., Reaven, L. B., and Stickgold, R. (2010). Cognitive replay of visuomotor learning at sleep onset: temporal dynamics and relationship to task performance. Sleep 1, 59-68.

Conflict of Interest Statement: The authors declare that the research was conducted in the absence of any commercial or financial relationships that could be construed as a potential conflict of interest.

The reviewer, KP-T, and handling Editor declared their shared affiliation, and the handling Editor states that the process nevertheless met the standards of a fair and objective review.

Copyright () 2016 Ortiz de Gortari and Griffiths. This is an open-access article distributed under the terms of the Creative Commons Attribution License (CC BY). The use, distribution or reproduction in other forums is permitted, provided the original author(s) or licensor are credited and that the original publication in this journal is cited, in accordance with accepted academic practice. No use, distribution or reproduction is permitted which does not comply with these terms. 